\title{
Hydrolysis and photolysis of insecticide metofluthrin in water
}

\author{
Masahiro NishiYama, Yusuke SuzukI* and Toshiyuki KaTAgI \\ Environmental Health Science Laboratory, Sumitomo Chemical Co., Ltd., \\ 4-2-1, Takatsukasa, Takarazuka, Hyogo 665-8555, Japan
}

(Received April 24, 2010; Accepted July 10, 2010)

\begin{abstract}
Metofluthrin [I, 2,3,5,6-tetrafluoro-4-(methoxymethyl)benzyl ( $E Z)-(1 R, 3 R)$-2,2-dimethyl-3-(prop-1-enyl)cyclopropanecarboxylate] was resistant to hydrolysis at $\mathrm{pH} 4$ and 7 but moderately hydrolyzed with a half-life of 36.8 days at $\mathrm{pH} 9$ and $25^{\circ} \mathrm{C}$ to form the corresponding acid and alcohol via ester cleavage. The activation energy was estimated to be $105 \mathrm{~kJ} \mathrm{~mol}^{-1}$ based on the hydrolysis rates at $25-50^{\circ} \mathrm{C}$. By continuous exposure to light at $>290$ $\mathrm{nm}$ from a Xenon arc lamp at hydrolytically stable $\mathrm{pH} 4$ and $25^{\circ} \mathrm{C}$, I was rapidly photodegraded with half-lives of 1.1-3.4 days, mainly via ester cleavage and successive oxidation followed by mineralization to carbon dioxide. Spectroscopic analyses together with co-chromatography with authentic standards showed that the major degradates having an ester linkage were the aldehyde and carboxylic acid derivatives formed via oxidative cleavage of the prop-1-enyl group together with the diol formed possibly through an oxidative intermediate, such as an epoxide. (C) Pesticide Science Society of Japan

Keywords: pyrethroid, metofluthrin, hydrolysis, photolysis, oxidation.
\end{abstract}

\section{Introduction}

Metofluthrin (I) $\left[\right.$ SumiOne ${ }^{\circledR}$, Eminence ${ }^{\circledR}, 2,3,5,6$-tetrafluoro4-(methoxymethyl)-benzyl (EZ)-(1R,3R)-2,2-dimethyl-3(prop-1-enyl)cyclopropanecarboxylate] is a new pyrethroid insecticide for public hygiene developed by Sumitomo Chemical Co., Ltd. ${ }^{1,2)}$ The eight isomers are possible for I due to the presence of two optically active centers and geometrical isomerization in its acid moiety. The active insecticide ingredient consists of $1 R$-trans isomers having the $E / Z$ geometrical composition of $1 / 8,{ }^{2)}$ abbreviated as RTE-I and RTZ-I. The extremely high knockdown activity against mosquitoes, high vaporizing property (vapor pressure of $1.96 \times 10^{-3} \mathrm{~Pa}$ at $25^{\circ} \mathrm{C}$ ) and low mammalian toxicity resulted in the development of new products, including a fan vaporizer, and paper and resin emanators used outdoors as well as indoors. ${ }^{2)}$ Incidentally, pyrethroids have been developed for agricultural usage and their behavior has been well investigated to identify their impact on the environment. Since most pyrethroids are carboxylic esters, they show moderate hydrolytic susceptibility under neutral conditions but generally undergo rapid alkaline hydrolysis via a $\mathrm{B}_{\mathrm{AC}} 2$ mechanism. ${ }^{3)}$ Many have a chrysan-

\footnotetext{
* To whom correspondence should be addressed.

E-mail: suzukiy16@sc.sumitomo-chem.co.jp

Published online August 18, 2010

(C) Pesticide Science Society of Japan
}

themic acid moiety very susceptible to direct photolysis by absorbing light energy. The typical reaction is photo-induced isomerization via homolytic cleavage of the $\mathrm{C}_{1}-\mathrm{C}_{3}$ bond in the cyclopropyl ring, and reactions with active oxygen species have been also reported ${ }^{4}$; however, much less information has been accumulated for pyrethroids intended for indoor use because of their very limited emission into the environment. I has a unique chemical structure both in acid and alcohol moieties different from the existing synthetic pyrethroids and hence, its environmental behavior should be examined to assess unexpected impacts when released into each area of the environment. Contamination of $\mathbf{I}$ in air would be most unlikely because of its rapid degradation, with a half-life of less than $2 \mathrm{~h}$, which can be estimated using the EPI-Suite software recommended by U.S. EPA. ${ }^{5)}$ We have reported the metabolic profiles of $\mathbf{I}$ in aerobic soil ${ }^{6)}$ but its behavior in an aqueous solution has not yet been clarified.

The objective of this study was to determine the hydrolytic and photolytic profiles of $\mathbf{I}$ in buffered aqueous solutions. The $R T Z$ isomer, as a major constituent of $\mathbf{I}$ labeled with ${ }^{14} \mathrm{C}$ in either acid or alcohol moiety, was conveniently subjected to hydrolysis study since the geometrical isomerism apart from hydrolytically susceptible ester linkage was unlikely to affect the hydrolytic profiles. The ${ }^{14} \mathrm{C}$-labeled $R T E$ was also utilized in aqueous photolysis to know the importance of photo-induced isomerization as well as possible differences in its degradation pathways. 


\section{Materials and Methods}

\section{Chemicals}

The RTZ and RTE isomers of $\mathbf{I}$ individually labeled with ${ }^{14} \mathrm{C}$ at $\alpha$-position of the 2,3,5,6-tetrafluoro-4-methoxymethylbenzyl group $\left(\right.$ Alc- ${ }^{14} \mathrm{C}$ ) or carbonyl carbon $\left(\right.$ Acid- ${ }^{14} \mathrm{C}$ ) were synthesized in our laboratory (Fig. 3). ${ }^{6}$ The specific activities of both isomers were 6.19 and $6.11 \mathrm{MBq} \mathrm{mg}^{-1}$, respectively. The radiochemical and optical purities were determined to be greater than $98.9 \%$ for all ${ }^{14} \mathrm{C}$ labels. The non-radiolabeled isomers of $\mathbf{I}$, the corresponding acids (RTZ-II and RTE-II) and alcohol (III) together with the oxidized esters (IV and V) were synthesized in our laboratory according to the reported methods. ${ }^{1,7)}$ IV: $\mathrm{MS} \mathrm{m} / z 349(\mathrm{M}+\mathrm{H})^{+} ;{ }^{1} \mathrm{H} \mathrm{NMR} \delta_{\mathrm{H}}\left(\mathrm{CDCl}_{3}\right)$ : $1.29\left(3 \mathrm{H}, \mathrm{s}\right.$, gem $\left.-\mathrm{CH}_{3}\right), 1.35\left(3 \mathrm{H}, \mathrm{s}\right.$, gem $\left.-\mathrm{CH}_{3}\right), 2.45(1 \mathrm{H}, \mathrm{d}$, C $\underline{\mathrm{HCHO}}$ ), 2.50 (1H, dd, $\mathrm{CHCOO}), 3.40\left(3 \mathrm{H}, \mathrm{s}, \mathrm{CH}_{3} \mathrm{O}\right), 4.59$ $\left(2 \mathrm{H}, \mathrm{s}, \mathrm{PhC}_{2} \mathrm{OC}(\mathrm{O})\right), 5.25\left(2 \mathrm{H}, \mathrm{s}, \mathrm{PhCH}_{2} \mathrm{OCH}_{3}\right), 9.59(1 \mathrm{H}$, s, CHO). V: MS $m / z 363(\mathrm{M}-\mathrm{H})^{-} ;{ }^{1} \mathrm{H} \mathrm{NMR} \delta_{\mathrm{H}}\left(\mathrm{CDCl}_{3}\right)$ : $1.31\left(3 \mathrm{H}, \mathrm{s}\right.$, gem $\left.-\mathrm{CH}_{3}\right), 1.32\left(3 \mathrm{H}, \mathrm{s}\right.$, gem $\left.-\mathrm{CH}_{3}\right), 2.25(2 \mathrm{H}, \mathrm{s}$, 1,3-positions of cyclopropyl-H), $3.41\left(3 \mathrm{H}, \mathrm{s}, \mathrm{CH}_{3} \mathrm{O}\right), 4.60$ $\left(2 \mathrm{H}, \mathrm{s}, \mathrm{PhCH}_{2} \mathrm{OC}(\mathrm{O})\right), 5.25\left(2 \mathrm{H}, \mathrm{s}, \mathrm{PhCH}_{2} \mathrm{OCH}_{3}\right)$. The diol derivative VI, consisting of four enantiomers, was synthesized by acid hydrolysis of the corresponding epoxide that was prepared by treating $\mathbf{I}$ with $m$-chloroperbenzoic acid in dichloromethane. ${ }^{8)}$ VI: $\mathrm{MS} m / z 417(\mathrm{M}+\mathrm{Na})^{+}, 412\left(\mathrm{M}+\mathrm{H}_{2} \mathrm{O}\right)^{+} ;{ }^{1} \mathrm{H}$ NMR $\delta_{\mathrm{H}}\left(\mathrm{CDCl}_{3}\right): 1.16-1.29\left(9 \mathrm{H}, \mathrm{m}\right.$, gem $\left.-\mathrm{CH}_{3} \times 2, \mathrm{CH}_{3} \mathrm{C}\right)$, 1.47-1.54 (1H, s, 3-position of cyclopropyl-H), $1.61(1 \mathrm{H}, \mathrm{d}$, 1-position of cyclopropyl-H), 2.15-2.42 (2H, br-s, OH), 3.05$3.10\left(1 \mathrm{H}, \mathrm{m}, \mathrm{C} \underline{\mathrm{H}}(\mathrm{OH}) \mathrm{CH}(\mathrm{OH}) \mathrm{CH}_{3}\right), 3.40\left(3 \mathrm{H}, \mathrm{s}, \mathrm{CH}_{3} \mathrm{O}\right)$, 3.66-3.79 (1H, m, $\left.\mathrm{CH}(\mathrm{OH}) \mathrm{CH}(\mathrm{OH}) \mathrm{CH}_{3}\right), 4.59(2 \mathrm{H}, \mathrm{s}$, $\left.\mathrm{PhCH}_{2} \mathrm{OC}(\mathrm{O})\right), 5.23\left(2 \mathrm{H}, \mathrm{s}, \mathrm{PhCH}_{2} \mathrm{OCH}_{3}\right)$; IR $v_{\text {max }}$ (neat, $\left.\mathrm{cm}^{-1}\right)$ : $3398(\mathrm{O}-\mathrm{H}), 1738(\mathrm{C}=\mathrm{O})$. The chemical purity of each standard was determined to be $>95 \%$ by high-performance liquid chromatography (HPLC). Pure water with an electrical resistivity of more than $16 \mathrm{M} \Omega \mathrm{cm}$ (Organo Co., Japan) was used to prepare $10 \mathrm{mM}$ buffers at $\mathrm{pH} 4$ (phosphate for hydrolysis, acetate for photolysis), 7 (tris(hydroxymethyl) aminomethane- $\mathrm{HCl}$ ) and 9 (borate), and the $\mathrm{pH}$ value was confirmed within \pm 0.2 of the nominal value with a Horiba F$15 \mathrm{pH}$ meter. Buffer solutions were sterilized by autoclaving for $20 \mathrm{~min}$ at $1.5 \mathrm{~kg} \mathrm{~cm}^{-2}$ and $120^{\circ} \mathrm{C}$ using an S-325 autoclave (Tomy Seiko Co.). All buffers and aqueous solutions of I used in the hydrolysis study were bubbled with nitrogen gas for 5 min prior to use to remove as much dissolved oxygen as possible.

\section{Spectroscopy}

The ultraviolet and visible (UV-Vis) absorption spectra of each isomer of I were measured in methanol at the concentration of $0.2-0.3 \mathrm{mM}$ with a Shimadzu UV-2550 UV-Vis spectrometer using a quartz cuvette $(1 \mathrm{~cm}$ path length). The proton nuclear magnetic resonance (NMR) spectrum was obtained in chloroform- $d_{1}$ containing tetramethylsilane (TMS) as an internal standard $(\delta 0.00 \mathrm{ppm})$ with a Varian Unity 300 spec- trometer at $300 \mathrm{MHz}$. Fourier-transformation infrared spectroscopy (FT-IR) spectrum was measured with a PerkinElmer Spectrum One spectrometer equipped with a universal ATR sampling accessory. Liquid chromatography-mass spectrometry (LC-MS) and LC-MS/MS were carried out to confirm the molecular structure of each degradate using a Hitachi M-1000 mass spectrometer equipped with an APCI interface at $180^{\circ} \mathrm{C}$ (methanol, $1 \mathrm{ml} \mathrm{min}^{-1}$ ) by direct injection and a ThermoFinningan TSQ Quantum mass spectrometer equipped with an ESI interface at $290^{\circ} \mathrm{C}$ and Cadenza CD-C18 column ( $3 \mu \mathrm{m}$, 4.6-mm i.d. $\times 150 \mathrm{~mm}$, Imtakt) (acetonitrile/0.1\% acetic acid gradient system; $0.2 \mathrm{ml} \mathrm{min}^{-1}$ ). The following gradient was used in LCMS/MS analysis with an Agilent 1100 HPLC system: $0 \mathrm{~min}, \% \mathrm{~A}$ (acetonitrile): \%B (0.1\% acetic acid), $5: 95$; 0 to $40 \mathrm{~min}$, linear, $95: 5$ at $40 \mathrm{~min}$; 40 to $45 \mathrm{~min}$, isocratic, $95: 5$ at $45 \mathrm{~min}$.

\section{Radioassay and chromatography}

The radioactivity in aliquots of organic and aqueous layers was determined by liquid scintillation counting (LSC) with a Packard Model 2000CA or 1600TR liquid scintillation counter equipped with an automatic external standard, by adding $10 \mathrm{ml}$ Packard Emulsifier Scintillator Plus ${ }^{\mathrm{TM}}$ in a low potassium glass vial. A 1-ml aliquot of ethylene glycol and $0.5 \mathrm{M} \mathrm{NaOH}$ in each volatile trap used through the photolysis study was taken separately in duplicate for radioassay. Furthermore, ${ }^{14} \mathrm{CO}_{2}$ in the alkaline trap was precipitated as $\mathrm{Ba}^{14} \mathrm{CO}_{3}$ by adding $20 \mathrm{ml}$ of $1.0 \mathrm{M} \mathrm{BaCl}_{2}$ to $20 \mathrm{ml}$ of $0.5 \mathrm{M}$ $\mathrm{NaOH}$ in the alkaline trap. The 2-ml aliquot of supernatant, separated by centrifugation at $2500 \mathrm{rpm}$ for $5 \mathrm{~min}$ with a HIMAC CR5B centrifuge (Hitachi), was taken in duplicate for radioassay to quantify ${ }^{14} \mathrm{CO}_{2}$. The background level of radioactivity in liquid scintillation counting was $1 \mathrm{~Bq}$.

The aqueous solution in hydrolysis and photolysis studies was directly analyzed by reversed-phase HPLC for either quantification of $\mathbf{I}$ and its degradates or their chemical identification. A Hitachi L-7100 pump equipped with a Sumipax ODS A-212 column $(5 \mu \mathrm{m}, 6-\mathrm{mm}$ i.d. $\times 150 \mathrm{~mm}$; Sumika Chemical Analysis Service, Ltd., Osaka) was operated at a flow rate of $1 \mathrm{ml} \mathrm{min}{ }^{-1}$. The following solvent program was used for typical analyses: $0 \mathrm{~min}, \% \mathrm{~A}$ (acetonitrile): \%B ( $0.05 \%$ formic acid), $5: 95$; 0 to $3 \mathrm{~min}$, isocratic; 3 to $5 \mathrm{~min}$, linear, $30: 70$ at $5 \mathrm{~min} ; 5$ to $25 \mathrm{~min}$, linear, $40: 60$ at $25 \mathrm{~min}$; 25 to $35 \mathrm{~min}$, linear, $95: 5$ at $35 \mathrm{~min} ; 35$ to $45 \mathrm{~min}$, isocratic. Each chemical in the effluent was also monitored at 230 or $270 \mathrm{~nm}$ with a Hitachi L-7400 UV detector. In order to examine the possible isomerization during each study, the fraction of I isolated from the aqueous solution was subjected to chiral HPLC analysis using SUMIPAX DI-NO 2 (5 $\mu \mathrm{m}, 4-\mathrm{mm}$ i.d. $\times 250 \mathrm{~mm}$; Sumika Chemical Analysis Service, Ltd., Osaka) and CHIRALCEL OD-H $(5 \mu \mathrm{m}, 4.6-\mathrm{mm}$ i.d. $\times 150$ mm; Daicel Chemical Industries, Ltd., Tokyo) columns under the same analytical conditions, as reported previously. $\left.{ }^{6}\right)$ The radioactivity of the column effluent was monitored with a 
flow scintillation radio detector Radiomatic 150TR (Packard Instrument Co.) with a 500- $\mu 1$ liquid cell using Ultima-Flo $\mathrm{AP}^{\circledR}$ (Packard Instrument Co.) as the scintillator. Each ${ }^{14} \mathrm{C}$ peak was identified by HPLC co-chromatography by comparing its retention time with those of non-radiolabeled authentic standards. Silica gel $60 \mathrm{~F}_{254}$ thin-layer plates $(200 \times 200 \mathrm{~mm}$, 0.25 -mm layer thickness; E. Merck) were used for two-dimensional (2D) co-chromatographic analysis with the solvent systems of A (chloroform/methanol; 9/1, v/v) and B (toluene/ ethyl formate/formic acid; 5/7/1, v/v/v). Autoradiograms were prepared by exposing the TLC plate to a BAS-III ${ }_{s}$ Fuji imaging plate (Fuji Photo Film Co., Ltd.) and the radioactivity in each spot was quantified using a Typhoon 9200 Variable Mode Imager (Amersham Biosciences). The typical retention times and $R_{\mathrm{f}}$ values of $\mathbf{I}$ and related degradates are listed in Table 1.

\section{Hydrolysis study}

The appropriate volumetric fraction of acetonitrile as a cosolvent used to prepare the aqueous solution of I was first examined because of its high hydrophobicity $(\log \mathrm{P}=5.64)$ and low water solubility $\left(0.73 \mathrm{ppm}\right.$ at $\left.20^{\circ} \mathrm{C}\right){ }^{2)}$ To prepare buffered aqueous solution of $\mathbf{I}$ at a nominal concentration of $0.5 \mathrm{ppm}$ less than its water solubility, the acetonitrile solution of [Alc$\left.{ }^{14} \mathrm{C}\right]$ RTZ-I was added to $20 \mathrm{ml}$ of each sterile buffer in $50-\mathrm{ml}$ Pyrex Erlenmeyer flasks as the volumetric fraction of acetonitrile became 1, 5 and $10 \%$, followed by mechanical shaking at room temperature in darkness up to $1 \mathrm{hr}$. An aliquot of each solution was subjected to radioassay in duplicate immediately after shaking and incubation for 1 day at $25^{\circ} \mathrm{C}$ to examine the actual concentration of $\mathbf{I}$. Based on this investigation, the test concentration was finally adjusted to $0.5 \mathrm{ppm}$ in the presence

Table 1. Chromatographic properties of $\mathbf{I}$ and its related degradates

\begin{tabular}{lccc}
\hline & & \multicolumn{2}{c}{$R_{\mathrm{f}}^{b)}$} \\
\cline { 3 - 4 } Compound & $\mathrm{R}_{\mathrm{t}}(\mathrm{min})^{a)}$ & $\mathrm{A}$ & $\mathrm{B}$ \\
\cline { 3 - 4 }$R T Z-\mathbf{I}$ & 42.4 & 0.72 & 0.69 \\
$R T E-\mathbf{I}$ & 42.4 & 0.72 & 0.69 \\
$R T Z-\mathbf{I I}$ & 29.8 & 0.40 & 0.56 \\
$R T E-$ II & 30.7 & 0.40 & 0.56 \\
III & 30.1 & 0.52 & 0.48 \\
IV & 38.5 & 0.70 & 0.60 \\
V & 36.3 & 0.38 & 0.52 \\
VI & 31.0 & $0.36,0.32$ & 0.45 \\
\hline
\end{tabular}

a) Typical reversed-phase HPLC retention time. In chiral analysis, the retention times of RTZ-I and RTE-I were 39.6 and 42.3 min, respectively. ${ }^{b)}$ TLC $R_{\mathrm{f}}$ values with indicated solvent systems. A, chloroform/methanol $(9 / 1, \mathrm{v} / \mathrm{v})$; B, toluene/ethyl formate/formic acid (5/7/1, v/v/v). of $10 \%(\mathrm{v} / \mathrm{v})$ acetonitrile as a water-miscible co-solvent. Except for the above test concentration and co-solvent volume, the hydrolysis study was conducted in accordance with the OECD guideline. ${ }^{9)}$ All glassware was sterilized by heating for $2 \mathrm{hr}$ at $180^{\circ} \mathrm{C}$ prior to use. Preparation and sampling of each buffered solution were aseptically conducted on a VRG1302L clean bench (Air Tech Japan, Ltd.). The buffered solution of $\left[\right.$ Alc- $\left.{ }^{14} \mathrm{C}\right] R T Z-I$ at each $\mathrm{pH}$ was individually incubated at $50 \pm 0.1^{\circ} \mathrm{C}$ in darkness for 5 days and its $0.5-1.0 \mathrm{ml}$ portion was subjected to LSC and HPLC analyses after $0,0.24 \mathrm{hr}$ and 5 days post-treatment. Each flask after 5-day incubation was rinsed with $10 \mathrm{ml}$ methanol to examine the sorption of $\mathbf{I}$ onto the glass surface and a portion of each rinsate was taken in duplicate for LSC followed by HPLC analysis. Since insignificant hydrolysis at $\mathrm{pH} 4$ and 7 was observed even at $50^{\circ} \mathrm{C}$, further hydrolysis was conducted at $25 \pm 0.1^{\circ} \mathrm{C}$ for 37 days and at $40 \pm 0.1^{\circ} \mathrm{C}$ for 9 days to identify the activation energy at $\mathrm{pH} 9$. A hydrolysis study was similarly conducted for [Acid$\left.{ }^{14} \mathrm{C}\right] R T Z$-I at $40 \pm 0.1^{\circ} \mathrm{C}$ for 9 days. In order to identify the chemical structures of degradates and to examine the possible isomerization of RTZ-I during hydrolysis, the remaining buffer solution after incubation at each $\mathrm{pH}$ and temperature was extracted twice with an approximately equal volume of ethyl acetate. After the radioassay of organic and aqueous layers by LSC, the concentrated extract was subjected to 2DTLC co-chromatography with authentic standards. The corresponding fraction of RTZ-I was scrapped off from the plate and extracted with acetonitrile for chiral HPLC analysis.

\section{Photolysis study}

The aqueous photolysis of I was conducted at hydrolytically stable $\mathrm{pH} 4$ in the presence of $10 \%$ acetonitrile by using $R T Z$ and RTE isomers individually labeled at acid and alcohol moieties. The concentration of I was adjusted to $0.5 \mathrm{ppm}$. According to the possible adsorption of $\mathbf{I}$ onto the surface of the test vessel, a batch study was conducted. A sterile $50-\mathrm{ml}$ buffer solution (10 mM acetate buffer) of each $\left[{ }^{14} \mathrm{C}\right]-\mathbf{I}$ was prepared similarly to the hydrolysis study and aseptically transferred into 100-ml cylindrical reaction vessels with the top covered by a Pyrex glass plate (4-mm thickness) to cut off UV light with wavelengths below $290 \mathrm{~nm}$. The details of the photolysis instrument have been reported previously. ${ }^{10)}$ In order to trap volatile ${ }^{14} \mathrm{C}$, carbon dioxide-free and water-saturated air was continuously passed over the buffer solution into gas-washing bottles, each containing $100 \mathrm{ml}$ ethylene glycol and $0.5 \mathrm{M}$ $\mathrm{NaOH}$ linked in series. The buffer solutions were continuously irradiated for 7 days utilizing a 2-kW xenon arc lamp (UXL-25SC; Ushio Inc., Tokyo) with spectral energy distribution similar to that of natural sunlight, as evidenced by measurement with a USR-20B spectroradiometer (Ushio). Integrated irradiance at 300 to $400 \mathrm{~nm}$ was measured to be $25.55-30.76 \mathrm{~W} \mathrm{~m}^{-2}$ during exposure for each label and was almost constant throughout the experiments. The buffer solutions were gently stirred during exposure and the temperature 
was maintained at $25 \pm 1^{\circ} \mathrm{C}$ by immersing the reaction vessel in a thermostatic water bath. A dark control using $\left[\mathrm{Alc}-{ }^{14} \mathrm{C}\right.$ ] both isomers was separately conducted similarly as above but with the reaction vessels wrapped in aluminum foil. An aliquot of each buffer solution was periodically taken for radioassay by LSC and direct HPLC analysis. After exposure, each vessel was rinsed with $10 \mathrm{ml}$ methanol and the concentrated rinsate was similarly analyzed to quantify the compound adsorbed onto the glass surface. The remaining solution was also extracted twice with ethyl acetate similarly to the hydrolysis study to analyze degradates by 2D-TLC and to examine the possible isomerization of $\mathbf{I}$ by chiral HPLC. In the case of [Acid- ${ }^{14} \mathrm{C}$ ], extraction was conducted after acidification at $\mathrm{pH} 1-2$. At each sampling time, the volatile ${ }^{14} \mathrm{C}$ in each volatile trap was quantified by LSC. Dark control samples were similarly analyzed after 7-day incubation.

To characterize the chemical structure of VI, HPLC-isolated fractions originating from day 7 samples of $\left[\mathrm{Alc}-{ }^{14} \mathrm{C}\right.$ ] and [Acid- $\left.{ }^{14} \mathrm{C}\right]$-I were hydrolyzed by $1 \mathrm{M} \mathrm{NaOH}$ overnight at room temperature and a portion of the reaction mixture was subjected to 2D-TLC. Furthermore, a large amount of degradate was prepared for the chemical identification of VI. [Alc$\left.{ }^{14} \mathrm{C}\right]$ RTE-I $(50 \mu \mathrm{g})$ and its unlabeled standard $(10 \mathrm{mg})$ were dissolved in $1000 \mathrm{ml}$ of $10 \mathrm{mM}$ acetate buffer at $\mathrm{pH} 4$ in the presence of $10 \%$ acetonitrile and the solution was irradiated by a $2-\mathrm{kW}$ xenon arc lamp for 7 days under continuous air flow. The resultant reaction mixture was extracted twice with $200 \mathrm{ml}$ diethyl ether and the corresponding VI fraction isolated from the concentrated extracts by HPLC was subjected to LC-MS analysis. In addition, VI $(10-20 \mu \mathrm{g})$, photolytically prepared as above, was acetylated in acetonitrile by treating with acetic anhydride in the presence of pyridine overnight and also subjected to LC-MS analysis. The two major bands (VI-1 and VI-2) detected by 1D-TLC analysis of the isolated VI using solvent system A were isolated from the plate and analyzed by LC-MS and MS/MS.

\section{Calculations}

The first-order rate constants $\left(k\right.$ in day $\left.{ }^{-1}\right)$ and half-lives $\left(\mathrm{T}_{1 / 2}\right.$ in day) of $\mathbf{I}$ were estimated by the least-square approximation method using the following equations, $\ln (C / 100)=-k t+b$ and $\mathrm{T}_{1 / 2}=-0.693 / k$, where $C$ is the percent of the summed $\mathbf{I}$ detected in the aqueous solution and rinsate of the reaction vessel, and $b$ is a constant. The temperature dependence of the hydrolysis rate was evaluated using the Arrhenius equation, $\ln k=\ln A-(E / R) / \mathrm{T}$, where $A$ is a frequency factor, $E$ is the energy of activation, $R$ is the gas constant $\left(8.314 \mathrm{~J} \mathrm{~mol}^{-1}\right.$ $\mathrm{K}^{-1}$ ) and $\mathrm{T}$ is the absolute temperature in $\mathrm{K}$. The photolytic half-life of $\mathbf{I}$ at the desired latitude and season was then calculated based on its quantum yield $(\Phi(\mathbf{I}))$ and its molar absorptivity at each wavelength values using the GCSOLAR program. $^{11,12)}$

\section{Results}

\section{Hydrolytic profiles of $\boldsymbol{I}$}

The ${ }^{14} \mathrm{C}$ recovery after $1-\mathrm{hr}$ mechanical shaking was 61.4 $69.8 \%, 86.6-90.2 \%$ and $98.5-98.9 \%$ of the applied ${ }^{14} \mathrm{C}$ in the presence of 1,5 and $10 \%$ acetonitrile and was insensitive to the $\mathrm{pH}$ tested. HPLC showed that $98.7-100.5 \%$ of ${ }^{14} \mathrm{C}$ in glass rinsates was I by itself and the reduced recovery at a lower volume of co-solvent was due to the adsorption of $\mathbf{I}$ onto the glass surface. The ${ }^{14} \mathrm{C}$ recovery from $10 \%$ acetonitrile solution was also determined to be $96.6-99.9 \%$ consisting of I after 1-day incubation. Under this condition, good ${ }^{14} \mathrm{C}$ recovery was found at $25^{\circ} \mathrm{C}(98.6-100.5 \%), 40^{\circ} \mathrm{C}(101.5-106.6 \%)$ and $50^{\circ} \mathrm{C}(97.9-105.1 \%)$ throughout the hydrolysis study and the adsorbed ${ }^{14} \mathrm{C}$ amounted to less than $6 \%$. [Alc- ${ }^{14} \mathrm{C}$ ] RTZ-I was stable at $\mathrm{pH} 4$ and 7 after incubation at $50^{\circ} \mathrm{C}$ for 5 days with greater than $96 \%$ of recovered ${ }^{14} \mathrm{C}$ as the unchanged RTZ-I. A single degradate was formed at $\mathrm{pH} 7$ but at only $1.3 \%$. In contrast, $R T Z$-I fell to $22.1 \%$ of the applied ${ }^{14} \mathrm{C}$ at $\mathrm{pH} 9$ after 5 days with concomitant formation of the degradate finally amounting to $82.9 \%$. This degradate was confirmed to be III by HPLC and 2D-TLC co-chromatography with an authentic standard. III gradually increased at $\mathrm{pH} 9$ to $49.9 \%$ at $25^{\circ} \mathrm{C}$ after 37 days and $73.0 \%$ at $40^{\circ} \mathrm{C}$ after 9 days without any formation of other degradates at greater than $1.0 \%$, as shown in Fig 1. At pH 9 and $40^{\circ} \mathrm{C}$, [Acid- ${ }^{14} \mathrm{C}$ ] RTZ-I gradually fell to $38.8 \%$ of the applied ${ }^{14} \mathrm{C}$ with concomitant formation of $R T Z$ II finally amounting to $62.2 \%$ after 9 days, and none of other degradates amounted to greater than $1.0 \%$. Chiral HPLC of the isolated $R T Z$-I from any sample showed no isomerization throughout hydrolysis. The hydrolysis rates of $\mathbf{I}$ at $\mathrm{pHs} 4$ and 7 could not be precisely estimated due to insignificant degradation, but the half-lives $\left(\mathrm{T}_{1 / 2}\right)$ were reasonably considered to be over 1 year at $25^{\circ} \mathrm{C}$ because of $<10 \%$ degradation at $50^{\circ} \mathrm{C}$ within 5 days. ${ }^{9)}$ The $k$ and $\mathrm{T}_{1 / 2}$ values at $\mathrm{pH} 9$ were estimated with good coefficients of correlation, as listed in Table 2. By applying the Arrhenius equation, the activation energy at $\mathrm{pH}$

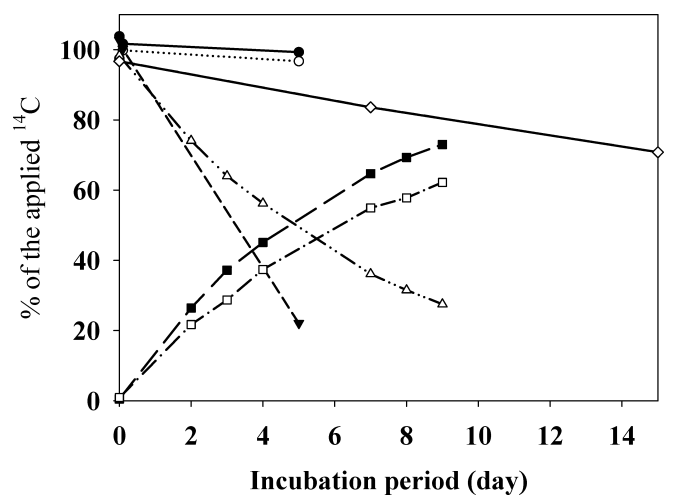

Fig. 1. Hydrolytic profiles of $\left[{ }^{14} \mathrm{C}\right] R T Z-\mathbf{I}$.

RTZ-I: - $-\mathrm{pH} 4$ and $50^{\circ} \mathrm{C} ; \bigcirc \cdots \cdots . \mathrm{O}, \mathrm{pH} 7$ and $50^{\circ} \mathrm{C} ; \mathbf{\nabla}---\nabla, \mathrm{pH}$ 9 and $50^{\circ} \mathrm{C} ; \triangle-\cdot-\triangle, \mathrm{pH} 9$ and $40^{\circ} \mathrm{C} ; \diamond-\diamond, \mathrm{pH} 9$ and $25^{\circ} \mathrm{C}$. II: $\square-\cdot \square$, pH 9 and $40^{\circ} \mathrm{C}$. III: $\square---\square$, pH 9 and $40^{\circ} \mathrm{C}$. 
Table 2. Hydrolytic rate constants and half-lives of $\mathbf{I}$

\begin{tabular}{cllcc}
\hline \multirow{2}{*}{ Temp. $\left({ }^{\circ} \mathrm{C}\right)$} & \multicolumn{4}{c}{ Hydrolysis of RTZ-I at pH 9 } \\
\cline { 2 - 5 } & Label & $k^{a)}$ & $\mathrm{T}_{1 / 2}{ }^{b)}$ & $\mathrm{r}^{2}$ \\
\hline 25 & Alc- ${ }^{14} \mathrm{C}$ & 0.019 & 36.8 & 0.999 \\
40 & Alc- ${ }^{14} \mathrm{C}$ & 0.14 & 4.9 & 0.999 \\
40 & Acid- $-{ }^{14} \mathrm{C}$ & 0.11 & 6.2 & 0.996 \\
50 & Alc- ${ }^{14} \mathrm{C}$ & 0.31 & 2.3 & 0.999 \\
\hline
\end{tabular}

${ }^{a)}$ Rate constant in day ${ }^{-1} \cdot{ }^{b)}$ Half-life in day.

9 was estimated to be $105 \mathrm{~kJ} \mathrm{~mol}^{-1}$. Based on these results, RTZ-I, a major constituent of $\mathbf{I}$, was considered to be resistant to hydrolysis at acidic and neutral $\mathrm{pHs}$ but to undergo alkaline hydrolysis via cleavage of the ester linkage to form RTZ-II and III without any isomerization.

\section{Photolytic profiles of $\boldsymbol{I}$}

The distribution of radioactivity in the photolysis study using each radiolabel is summarized in Table 3. The total recovery of ${ }^{14} \mathrm{C}$ was mostly greater than $90 \%$ of the applied ${ }^{14} \mathrm{C}$. In some cases, the adsorbed ${ }^{14} \mathrm{C}$ amounted to around $10 \%$ due to the high adsorptivity of I onto the glass surface. HPLC of the rinsates from the glass surface for either label sample showed that the adsorbed ${ }^{14} \mathrm{C}$ mainly considered of $\mathbf{I}$ and the other constituents amounted to less than $2.2 \%$ of the applied ${ }^{14} \mathrm{C}$. As with exposure to UV light, the acid moiety of I was found to be gradually mineralized to carbon dioxide, amounting to $16.6-17.7 \%$ after 7 days, while its alcohol moiety was much less mineralized $(<2 \%)$. Throughout the study, trace amounts of other volatiles were formed. Under dark conditions, no degradation of $\mathbf{I}$ was observed with the recovered ${ }^{14} \mathrm{C}$ as the unchanged I (data not shown). I underwent rapid photodegradation with half-lives of 1.1-3.4 days for RTZ-I and 1.7-2.7 days for $R T E$-I estimated by the least-square approximation method, as listed in Table 4 . The rapid photolysis rate made it difficult to find any difference between the two isomers. Chiral HPLC of the fraction due to $\left[\mathrm{Alc}-{ }^{14} \mathrm{C}\right]-\mathrm{I}$ showed that photo-induced isomerization at the acid moiety was not significant. After 4-day exposure of $\left[\mathrm{Alc}-{ }^{14} \mathrm{C}\right] R T Z-\mathbf{I}$, the $R T Z$ isomer was found to be predominant, with each of the other seven isomers amounting to $0.1-0.5 \%$. Similar profiles were observed for RTE-I. The UV-Vis spectra of I showed the absorption maximum at $273 \mathrm{~nm}\left(\varepsilon=1702 \mathrm{M}^{-1} \mathrm{~cm}^{-1}\right)$ and 274 $\mathrm{nm}\left(\varepsilon=1892 \mathrm{M}^{-1} \mathrm{~cm}^{-1}\right)$ for $R T Z-\mathbf{I}$ and $R T E-\mathbf{I}$, respectively, with the measurable shoulder extending to about $330 \mathrm{~nm}$ ( $\left.\varepsilon=10-20 \mathrm{M}^{-1} \mathrm{~cm}^{-1}\right)$; therefore, direct photolysis by light absorption was likely to have contributed to the dissipation of $\mathbf{I}$. In contrast to the lower contribution of photo-isomerization, either photo-induced cleavage of the ester linkage or oxidation at the prop-1-enyl group of the acid moiety controlled the photodegradation of I. III formed via ester cleavage amounted to $14.9-21.6 \%$ after 7-day exposure but the corresponding acid II could not be detected. Since the mineralization to $\mathrm{CO}_{2}$ from [Acid- ${ }^{14} \mathrm{C}$ ]-I samples was more significant than that from $\left[\mathrm{Alc}-{ }^{14} \mathrm{C}\right]-\mathbf{I}$ ones, II was most likely to be rapidly photodegraded under the tested conditions.

The other main photoproducts were IV, V and VI, formed through oxidation of the prop-1-enyl group with their relative extents fluctuating among the labels and isomers. Since the photo-oxidation of the isobutenyl group of chrysanthemic moiety to aldehyde and carboxyl ones has been reported for phenothrin, ${ }^{7)} \mathbf{I V}$ and $\mathbf{V}$ were identified using the corresponding synthetic standards through HPLC and 2D-TLC co-chromatography. As for VI, a sufficient amount for instrumental analyses was separately prepared and isolated as a single fraction with its equivalency to the photolysates being confirmed by HPLC. The FT-IR spectrum showed absorption at 3398 and $1738 \mathrm{~cm}^{-1}$, indicating the presence of hydroxyl and carboxyl groups, respectively. Further analysis by TLC with development system A (chloroform/methanol; 9/1, v/v) revealed that this HPLC single fraction consisted of two major components, VI-1 and VI-2, in almost the same amount. LC-MS and MS/MS analyses exhibited identical fragment patterns of these components and the MS spectra of VI-1 are shown in Fig. 2. Mass fragments in the LC-MS in positive ESI mode were observed at $\mathrm{m} / \mathrm{z} 412\left[\mathrm{M}+\mathrm{NH}_{4}\right]^{+}, 417[\mathrm{M}+\mathrm{Na}]^{+}, 806[2 \mathrm{M}+$ $\left.\mathrm{NH}_{4}\right]^{+}, 811[2 \mathrm{M}+\mathrm{Na}]^{+}$(Fig 2 (a)). LC-MS/MS analysis in the same mode and collision energy of $20 \mathrm{~V}$ against $\mathrm{m} / \mathrm{z} 806 \mathrm{re}-$ sulted in fragment peaks at $m / z 207,287,319,377$ and 412, each of which was identified as shown in Fig. 2 (b). In order to further confirm the chemical structure of VI, the isolated fraction originating from $\left[\mathrm{Alc}-{ }^{14} \mathrm{C}\right]-\mathrm{I}$ was either hydrolyzed with 1 $\mathrm{M} \mathrm{NaOH}$ or acetylated. The 2D-TLC analysis of hydrolysate showed the formation of a single product and was identified as III using a synthetic standard. Furthermore, the LC-MS spectrum of acetylated VI in positive ESI mode showed that two hydroxyl groups exist in VI, as evidenced from the fragments at $\mathrm{m} / z 418$ [diacetylated $\left.\mathrm{VI}-\mathrm{CH}_{3} \mathrm{COOH}\right]^{+}, 478$ [diacetylated $\mathrm{VI}]^{+}$. Based on these analytical results, VI was considered most likely to be the diol derivative of $\mathbf{I}$, as shown in Fig. 3, and this was confirmed by TLC and HPLC co-chromatography with the authentic standard. The other unknown photoproduct (Uk) eluted at $19.2 \mathrm{~min}$ in HPLC analysis was detected as a minor photodegradate. The amounts of Uk were $2-8 \%$ of the applied ${ }^{14} \mathrm{C}$ after 4-7 days from both isomers and labels, and the samples for instrumental analyses were similarly prepared as VI. Attempts to obtain a clear LC/MS spectrum failed but Uk prepared from $\left[\mathrm{Alc}-{ }^{14} \mathrm{C}\right]-\mathbf{I}$ was hydrolyzed to III. In contrast, two degradates were obtained from Uk originating from [Acid- ${ }^{14} \mathrm{C}$ ]-I. Acetylation of Uk resulted in the formation of two less polar compounds, as evidenced by 2D-TLC analysis; therefore, Uk was likely to be a derivative differently oxidized at the acid moiety from that in VI.

Based on these results, the photodegradation pathways of $\mathbf{I}$ are proposed in Fig. 3. On exposure to a xenon arc lamp as ar- 


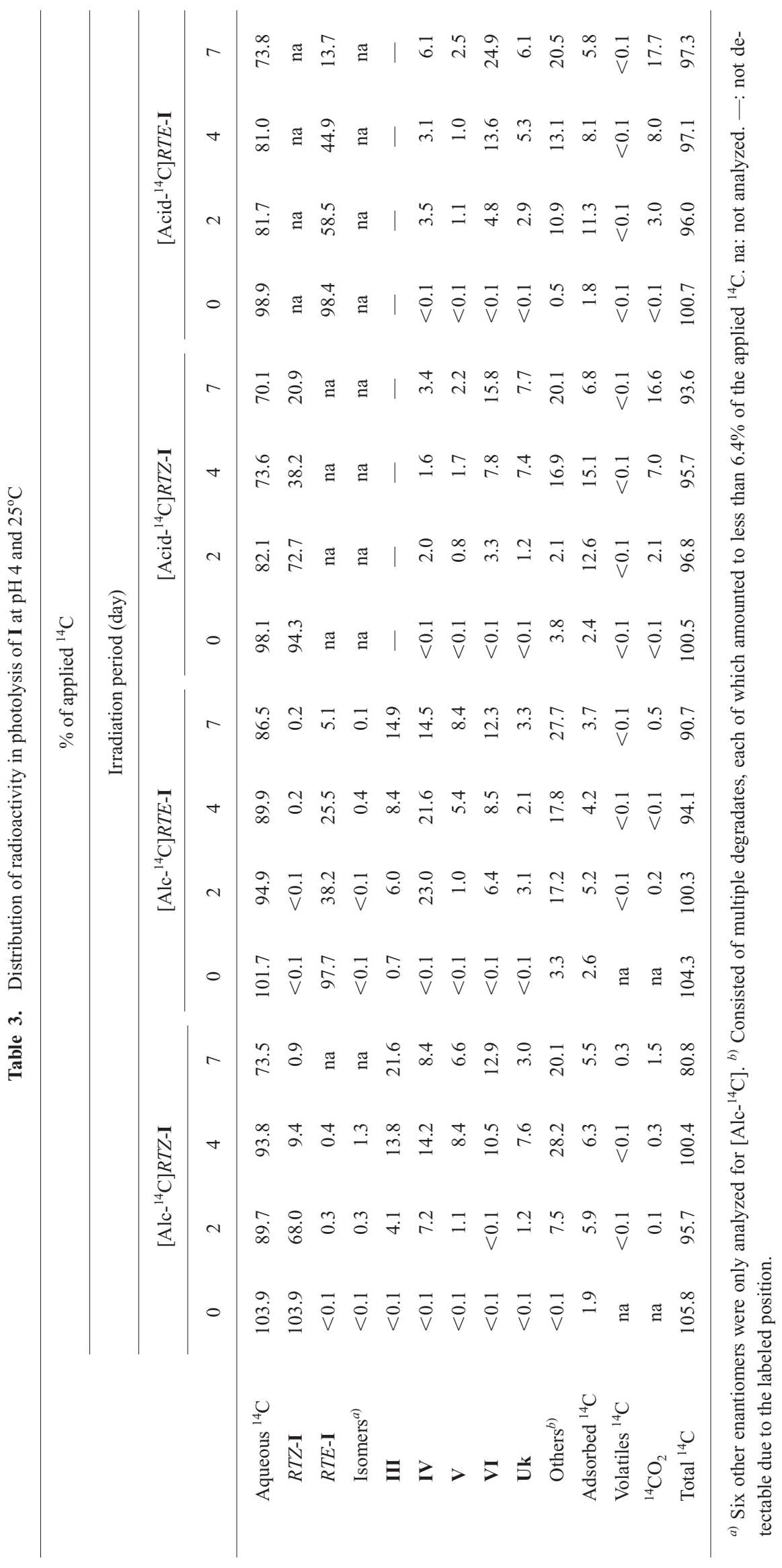


Table 4. Photolytic rate constants and half-lives of $\mathbf{I}$

\begin{tabular}{ccccc}
\hline \multirow{2}{*}{ Isomer } & \multicolumn{4}{c}{ Photolysis } \\
\cline { 2 - 5 } & Lable & $k^{a)}$ & $\mathrm{T}_{1 / 2}{ }^{b)}$ & $\mathrm{r}^{2}$ \\
\hline \multirow{2}{*}{ RTZ-I } & Alc- ${ }^{14} \mathrm{C}$ & 0.62 & 1.1 & 0.962 \\
& Acid- ${ }^{14} \mathrm{C}$ & 0.20 & 3.4 & 0.970 \\
& Alc- ${ }^{14} \mathrm{C}$ & 0.40 & 1.7 & 0.983 \\
& Acid- ${ }^{14} \mathrm{C}$ & 0.26 & 2.7 & 0.959 \\
\hline
\end{tabular}

${ }^{a)}$ Rate constant in day ${ }^{-1} \cdot{ }^{b)}$ Half-life in day. tificial sunlight, I rapidly underwent either photo-induced cleavage of ester linkage to form III or photo-oxidation of the double bond at the prop-1-enyl moiety to form IV, $\mathbf{V}$ and $\mathbf{V I}$. Photo-induced isomerization of $\mathbf{I}$ was very slight, with any other isomers not exceeding $1 \%$ of the applied ${ }^{14} \mathrm{C}$. The main hydrolytic product II formed via cleavage of ester linkage could not be detected and therefore, the acid moiety was likely to be immediately mineralized to ${ }^{14} \mathrm{CO}_{2}$ under UV exposure.

\section{Discussion}

In both hydrolysis and aquatic photolysis studies, some adsorption of I onto a glass surface was observed due to its high hydrophobicity (I: $\log \mathrm{P}=5.64$ ), similarly to other synthetic pyrethroids. ${ }^{3)}$ An adsorbed amount less than $6 \%$ of the applied ${ }^{14} \mathrm{C}$ is unlikely to markedly affect the estimation of hydrolytic profiles. I was resistant to hydrolysis at $\mathrm{pH} 4$ and 7 and relatively susceptible at $\mathrm{pH} 9$, which is the typical profile

(a)

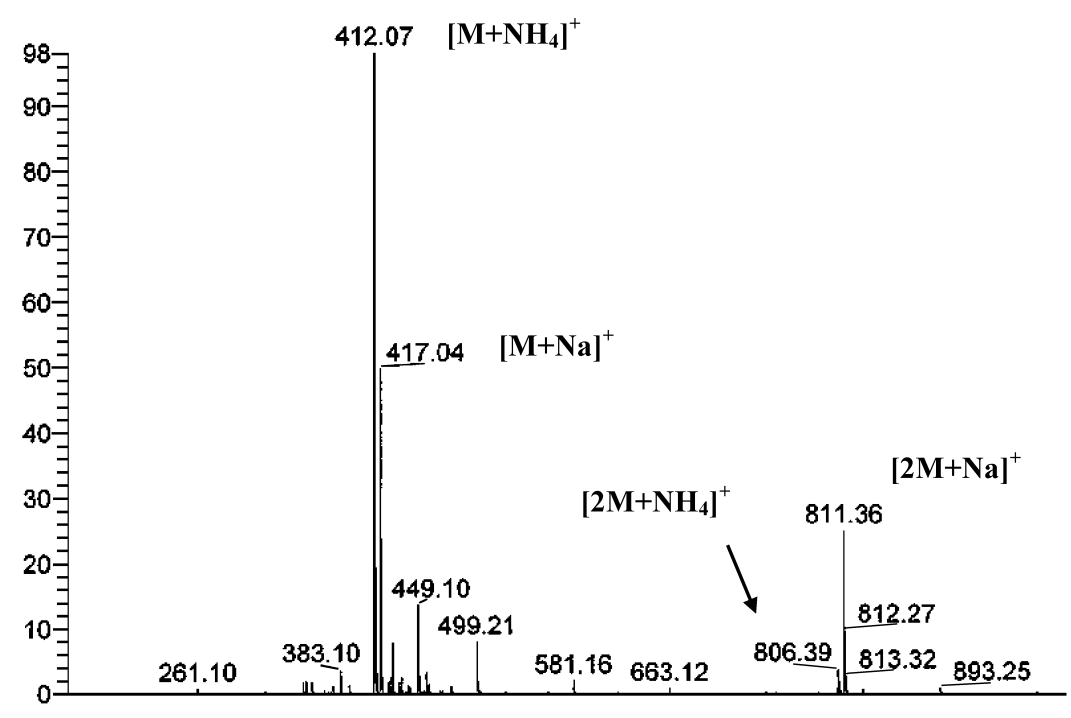

(b)

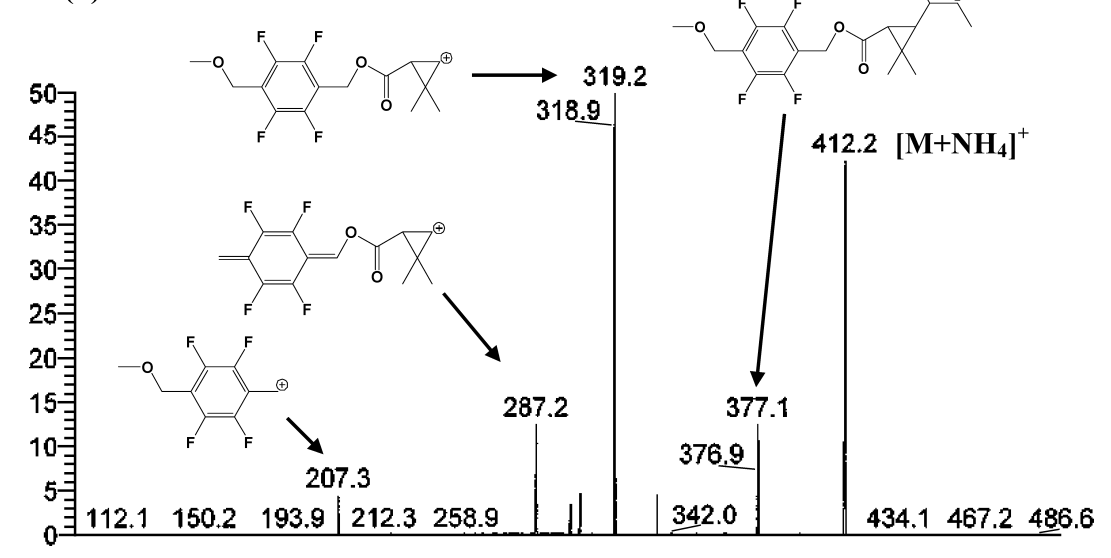

Fig. 2. LC-MS (a) and MS/MS (b) spectra of VI in positive ESI mode. (b) Precursor ion at $\mathrm{m} / \mathrm{z} 806$ with a collision energy of $20 \mathrm{~V}$. 


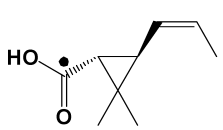

$R T Z$-II

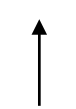

$\uparrow$

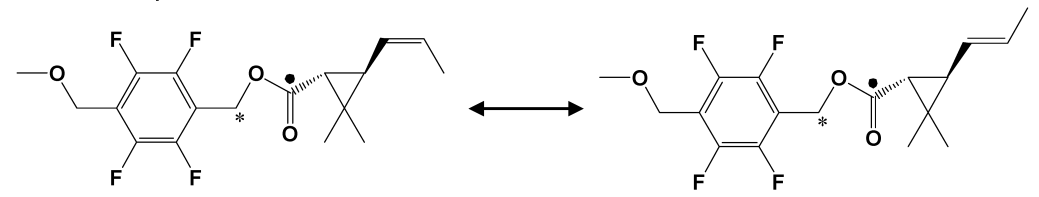

RTZ-I

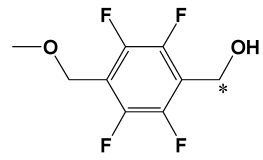

III

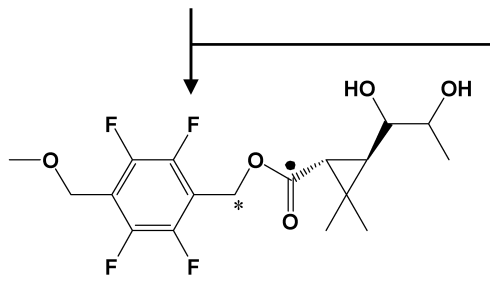

VI

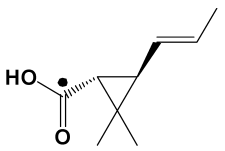

$R T E-\mathbf{I I}$

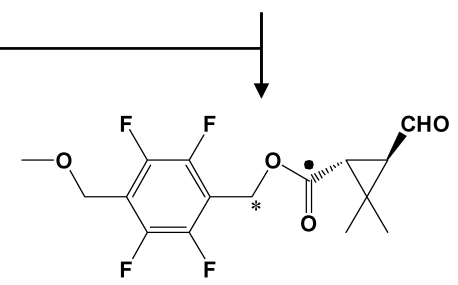

IV

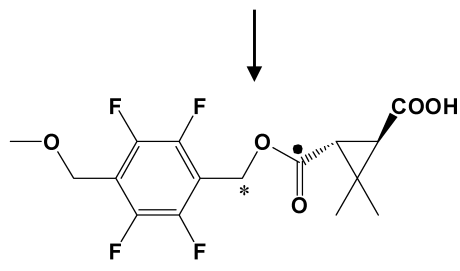

V

- ${ }^{14} \mathrm{C}$ labeled position of $\left[\mathrm{Acid}-{ }^{14} \mathrm{C}\right]$ labels

$*:{ }^{14} \mathrm{C}$ labeled position of $\left[\right.$ Alc- $\left.{ }^{14} \mathrm{C}\right]$ labels

Fig. 3. Proposed degradation pathways of $\mathbf{I}$ in hydrolysis and photolysis.

of a carboxylic ester. The hydrolytic half-life of 36.8 days at $\mathrm{pH} 9$ and $25^{\circ} \mathrm{C}$ is comparable to those of transfluthrin and tefluthrin having a similar tetrafluorobenzyl moiety and shorter than that of permethrin, ${ }^{3)}$ which originated from a more electron-withdrawing effect by tetrafluoro substitution at the phenyl ring. Although the activation energy of pyrethroid is not available, the obtained value of $105 \mathrm{~kJ} \mathrm{~mol}^{-1}$ is close to the upper limit of the reported values of many chemicals. ${ }^{13)}$ Therefore, the hydrolytic route is of less importance in the dissipation of $\mathbf{I}$ in an aquatic environment. In photolysis study, the aqueous solution was irradiated vertically from the top of each cylindrical vessel and photolysis on the glass surface would be of minor importance, as evidenced by the adsorbed ${ }^{14} \mathrm{C}$ remaining as unchanged I by HPLC of glass rinsates. One of the characteristics of $\mathbf{I}$ is high vapor pressure, but slight loss, possibly via azeotropic distillation, was observed during the photolysis study.

The photolytic profiles of both isomers were almost identical to their short half-lives under the tested conditions,
1.1-3.6 days. In order to estimate the photodegradation rates under a real environment, the quantum yield of $\mathbf{I}$ in aquatic photolysis was measured using a mixture of $p$-nitroacetophenone (PNAP) and pyridine at respective concentrations of $9.59 \mu \mathrm{M}$ and $11 \mathrm{mM}$ as a chemical actinometer. ${ }^{14,15)}$ Under this condition, the quantum yield $(\Phi)$ of PNAP was calculated to be $1.86 \times 10^{-4}$, and $\Phi$ of I was estimated to be 0.125 using light irradiance and molar absorptivity of $\mathbf{I}$ and PNAP. This value is between those of phenothrin (0.07) and $S$-bioallethrin (0.216) having the chrysanthemic acid moiety. ${ }^{16)}$ Using the quantum yield and the absorptivity of $\mathbf{I}$, its half-life under sunlight exposure could be calculated by the GCSOLAR program to be 2.9 days (spring), 2.3 days (summer), 5.3 days (fall), and 9.9 days (winter) at $40^{\circ} \mathrm{N}$ latitude, indicating the rapid photolysis of $\mathbf{I}$ in an aquatic environment under natural sunlight.

The photo-induced isomerization of $\mathbf{I}$ is considered to proceed via homolytic cleavage of the $\mathrm{C}_{1}-\mathrm{C}_{3}$ bond in the cyclopropyl ring, similarly to other pyrethroids ${ }^{4)}$ and various iso- 
mers were detected by chiral HPLC, but their formation was of minor importance during exposure. Since the alcohol moiety of $\mathbf{I}$ is resistant to photolysis because of the tetrafluoro substitution, many unknown products would be formed via reactions at the acid moiety with concomitant ester cleavage, and ring opening would result in more mineralization from [Acid- $\left.{ }^{14} \mathrm{C}\right]-\mathbf{I}$, as reported for phenothrin ${ }^{7)}$ and permethrin. ${ }^{17)}$ The main oxidized photoproducts are considered to be formed by direct photolysis of $\mathbf{I}$, and in the photo-excited state ozonolysis is most likely since the concentration of ozone in ambient air is known to be $10-70 \mathrm{ppb}^{4,18)}$ Ruzo et al. ${ }^{7,19)}$ have reported the facile photo-reaction of ozone at the isobutenyl group of chrysanthemic esters, leading to the formation of the corresponding aldehyde derivative through the ozonide intermediate. The successive carboxylic compound, $\mathbf{V}$, was considered to be formed via oxidation of IV by a reaction with molecular oxygen dissolved in aqueous media. As an alternative photolytic pathway, epoxidation of the isobutenyl group is also known to proceed by a reaction with ozone or molecular oxygen ${ }^{7}$ and the following hydrolysis is considered to form the diol derivative in aqueous solution. In our study, VI showed a single HPLC peak but two major bands having almost identical radioactivity by TLC analysis. Therefore, these four possible enantiomers are considered not to be resolved in reversed-phase HPLC but a pair of two enantiomers (VI-1 and VI-2) were detected on TLC, which was also evidenced by the same LC-MS and MS/MS fragment patterns between them. As the ground-state reaction of I, the double bond at the prop-1-enyl moiety is considered to be susceptible to reactive oxygen species as in the case of phenothrin and tetramethrin. ${ }^{7)}$ The main photoproduct IV can be synthesized by exposure to ozone in the presence of triphenylphosphine, which indicates a reaction through ozonide, whose existence was reported for the plant metabolism study of phenothrin. ${ }^{20)}$ This indicates that both direct and indirect photolytic reactions play an important role in the dissipation of I under environmental aquatic conditions.

\section{References}

1) K. Ujihara, T. Mori, T. Iwasaki, M. Sugano, Y. Shono and N. Matsuo: Biosici. Biotechnol. Biochem. 68, 170-174 (2004).

2) N. Matsuo, K. Ujihara, Y. Shono, T. Iwasaki, M. Sugano, T.
Yoshiyama and S. Uwagawa: SUMITOMO KAGAKU II, 1-15 (2005).

3) T. Katagi: Rev. Envion. Contam. Toxicol. 175, 79-261 (2002).

4) T. Katagi: Rev. Envion. Contam. Toxicol. 182, 1-195 (2004).

5) U.S.EPA: Estimation Programs Interface Suite ${ }^{\mathrm{TM}}$ for Microsoft ${ }^{\mathrm{B}}$ Windows, v 4.00. United States Environmental Protection Agency, Washington, DC, USA. http://www.epa.gov/opptintr/ exposure/pubs/episuite.htm

6) R. Kodaka, Y. Suzuki, T. Sugano and T. Katagi: J. Pestic. Sci. 32, 393-401 (2007).

7) L. O. Ruzo, I. H. Smith and J. E. Casida: J. Agric. Food Chem. 30, 110-115 (1982).

8) T. Ando, N. E. Jacobsen, R. F. Toia and J. E. Casida: J. Agric. Food Chem. 39, 600-605 (1991).

9) "OECD Guidelines for the Testing of Chemicals, Hydrolysis as a Function of pH," OECD Guideline 111, adopted $13^{\text {st }}$ April 2004.

10) R. Kodaka, T. Sugano and T. Katagi: Environ. Toxicol. Chem. 25, 310-316 (2006).

11) R. G. Zepp and D. M. Cline: Environ. Sci. Technol. 11, 359-366 (1977).

12) U.S.EPA: Exposure Assessment Models GCSOLAR, United States Environmental Protection Agency, Washington, DC, USA. http://www.epa.gov/ceampubl/swater/gcsolar/

13) J. C. Harris: "Handbook of Chemistry Property Estimation Methods,” W. J. Lyman, W. F. Reehl, D. H. Rosenblatt (eds), American Chemical Society, Washington DC, USA, Chapter 7 (1990).

14) M. Ponte, K. Shepler, M. Schick, A. Drakeford, R. Gonzalez and L. O. Ruzo: PTRL Project No. 1238W (2004).

15) U.S.EPA: Fate, Transport and Transformation Test Guidelines OPPTS 835.2210, Direct Photolysis Rate in Water by Sunlight, pp. 37, Office of Prevention, Pesticides and Toxic Substances, Environmental Protection Agency, Washington DC, USA (1998).

16) L. O. Ruzo and J. E. Casida: J Chem. Soc. Perkin I, 728-732 (1980).

17) R. L. Holmstead, J. E. Casida, L. O. Ruzo and D. G. Fullmer: $J$. Agric. Food Chem. 26, 590-595 (1978).

18) A. L. Garner, C. M. St Croix, B. R. Pitt, G. D. Leikauf, S. Ando and K. Koide: Nature Chem. 1, 316-321 (2009).

19) L. O. Ruzo, E. C. Kimmel and J. E. Casida: J. Agric. Food Chem. 34, 937-940 (1986).

20) K. Nambu, H. Ohkawa and J. Miyamoto: J. Pestic. Sci. 5, $177-$ 197 (1980). 